N O T E

\title{
The development of inversion in wh-questions: a reply to Van Valin*
}

\author{
CAROLINE F. ROWLAND \\ University of Liverpool \\ J ULIAN M. PINE \\ University of Nottingham
}

(Received 25 April 2002. Revised 26 Fuly 2002)

\begin{abstract}
Van Valin (Fournal of Child Language 29, 2002, I6I-75) presents a critique of Rowland \& Pine (Fournal of Child Language 27, 2000, I 57-8 I) and argues that the wh-question data from Adam (in Brown, A first language, Cambridge, MA, I 973) cannot be explained in terms of input frequencies as we suggest. Instead, he suggests that the data can be more successfully accounted for in terms of Role and Reference Grammar. In this note we re-examine the pattern of inversion and uninversion in Adam's wh-questions and argue that the RRG explanation cannot account for some of the developmental facts it was designed to explain.
\end{abstract}

\section{INTRODUCTION}

Van Valin's (2002) critique of Rowland \& Pine (2000, hereafter R\&P) argues that a theory of acquisition based on Role and Reference Grammar (RRG) provides a superior explanation of one child's wh-question data to the inputdriven explanation that we propose. In the present note we point out some weaknesses in Van Valin's own hypothesis and conclude that, although a legitimate alternative that fits neatly with the summary data presented in R\&P, closer examination of Adam's speech raises some doubts about Van Valin's claims.

[*] We would like to thank Elena Lieven, Anna Theakston and an anonymous reviewer for helpful comments on an earlier draft. Address for correspondence: Caroline Rowland, Department of Psychology, University of Liverpool, Bedford Street South, Liverpool, L69 7ZA, UK. tel: +44 (o)I5 794 I I20. e-mail: crowland@liverpool.ac.uk 
The focus of Van Valin's critique: data from Adam (Brown, I973) presented in Rowland $\xi^{\circ}$ Pine (2000)

In Rowland \& Pine (2000), we provided a critique of two accounts of subjectauxiliary inversion (non-inversion) errors in wh-question acquisition (de Villiers, I99I; Valian, Lasser \& Mandelbaum, I992) and presented an alternative explanation. On the basis of data from Adam (Brown, I973, available on the CHILDES database, MacWhinney, 2000), we argued that Adam's correctly inverted wh-questions (e.g. what are you doing?) and noninversion errors (e.g. what you can do?) came from largely different populations of wh-word + auxiliary (wh + aux) combinations. We then claimed that the pattern of inversion/non-inversion could be explained in terms of the relative frequency of particular wh-word + auxiliary combinations in Adam's input.

In his critique, Van Valin (2002) seems to accept that there is little overlap in the wh-word and auxiliary forms that occur in inverted and uninverted wh-questions and agrees that this is a finding that needs to be accounted for. However, he disagrees with our claim that the pattern of wh-question acquisition can be explained in terms of the frequency with which Adam hears particular wh + aux combinations. He presents three criticisms of our frequency-based explanation.

First, Van Valin argues that the pattern of inversion and non-inversion that is presented in Table 5 in $\mathrm{R} \& \mathrm{P}$ (reproduced in Table I) cannot be accounted for in terms of input frequencies. Our account stated that the distribution of inverted and uninverted wh-questions could be predicted from the relative frequency of wh + aux combinations in Adam's input. In support, we demonstrated that the wh + aux combinations that occurred inverted in Adam's data (e.g. what + are in what are you doing?) were of significantly higher frequency in the input than the combinations Adam used with non-inversion (e.g. what + can in what he can do?). We proposed that 'children will only produce correctly inverted wh-questions when they have been able to learn the relevant wh + aux combination necessary to produce the question from the input' (Rowland \& Pine, 2000, p. I77) and that non-inversion errors could be seen as 'instances of "groping" patterns (Braine, I976) said to be produced when the child attempts to construct a question for which s/he has not yet acquired the necessary knowledge' (Rowland \& Pine, 2000, p. I 79).

Van Valin argues that this input frequency explanation is insufficient because it cannot explain all of the wh + aux combinations produced by Adam. As can be seen from Table I, some of Adam's uninverted wh + aux combinations are of higher frequency (correctly inverted) in the input sample than those he produces inverted (e.g. why don't occurs 22 times in the input sample and yet is always produced in uninverted questions in the child). In addition, in Table I, I I of the inverted wh + aux combinations have an input frequency 
TABle i. DATA FROM ROWLAND \& Pine (2000) 'Table 5. Total no. of wh + aux combinations that occur inverted and/or uninverted during the noninversion period and their frequency in the input sample'

\begin{tabular}{lclccc}
\hline $\begin{array}{l}\text { Inverted } \\
\text { wh + aux }\end{array}$ & $\begin{array}{c}\text { No. in input } \\
\text { sample }\end{array}$ & $\begin{array}{c}\text { Uninverted } \\
\text { wh + aux }\end{array}$ & $\begin{array}{c}\text { No. in input } \\
\text { sample }\end{array}$ & $\begin{array}{c}\text { Inverted \& } \\
\text { uninverted } \\
\text { wh + aux }\end{array}$ & $\begin{array}{c}\text { No. in input } \\
\text { sample }\end{array}$ \\
\hline how could & $\circ$ & how can't & $\circ$ & why is & I \\
what was & $\circ$ & what can & $\circ$ & how \\
what have & $\circ$ & what may & 7 \\
what'has & $\circ$ & what shall & $\circ$ & \\
where'is & $\circ$ & what should & $\circ$ & \\
where had & $\circ$ & where should & $\circ$ & \\
where shall & $\circ$ & which should & $\circ$ & \\
which does & $\circ$ & why'is & $\circ$ & \\
who are & $\circ$ & why can & $\circ$ & \\
who're & $\circ$ & why can't & $\circ$ & \\
who do & $\circ$ & why couldn't & $\circ$ & \\
how does & 2 & why doesn't & $\circ$ & \\
what am & 2 & why'has & $\circ$ & \\
what is & 2 & why might & $\circ$ & \\
where could & 2 & why won't & $\circ$ & \\
what're & 4 & where will & I & \\
where do & 4 & what will & 3 & \\
how did & 5 & why didn't & 3 & \\
where does & 6 & why did & 6 & \\
why do & I3 & why don't & 22 & \\
how do & I & & & \\
what does & I 8 & & & \\
what did & I & & & \\
where did & 22 & & & \\
what are & 25 & & & \\
what do & 37 & & & \\
Total & I 75 & & & \\
\hline
\end{tabular}

of $\circ \%$. Van Valin states that:

'while the input data are only a sample, if they are at all representative of the overall pattern, then it is very difficult to see how the low input frequency of the top I I combinations in the inverted wh + aux column explains why they are consistently inverted, while the same low input frequency of the top I 5 combinations in the uninverted wh + aux column explains why they are consistently not inverted'. (Van Valin, 2002, p. I64)

Second, Van Valin contends that R\&P's input account cannot explain the pattern of wh-question acquisition in Adam's data illustrated in Figure I (reproduced from R\&P). Van Valin interprets Figure I as revealing some interesting facts about the acquisition sequence. He argues that Adam's first wh-questions with auxiliaries are more likely to be inverted than uninverted (at datapoints 2 and 3), Adam then starts to invert less often (at datapoint 4), 


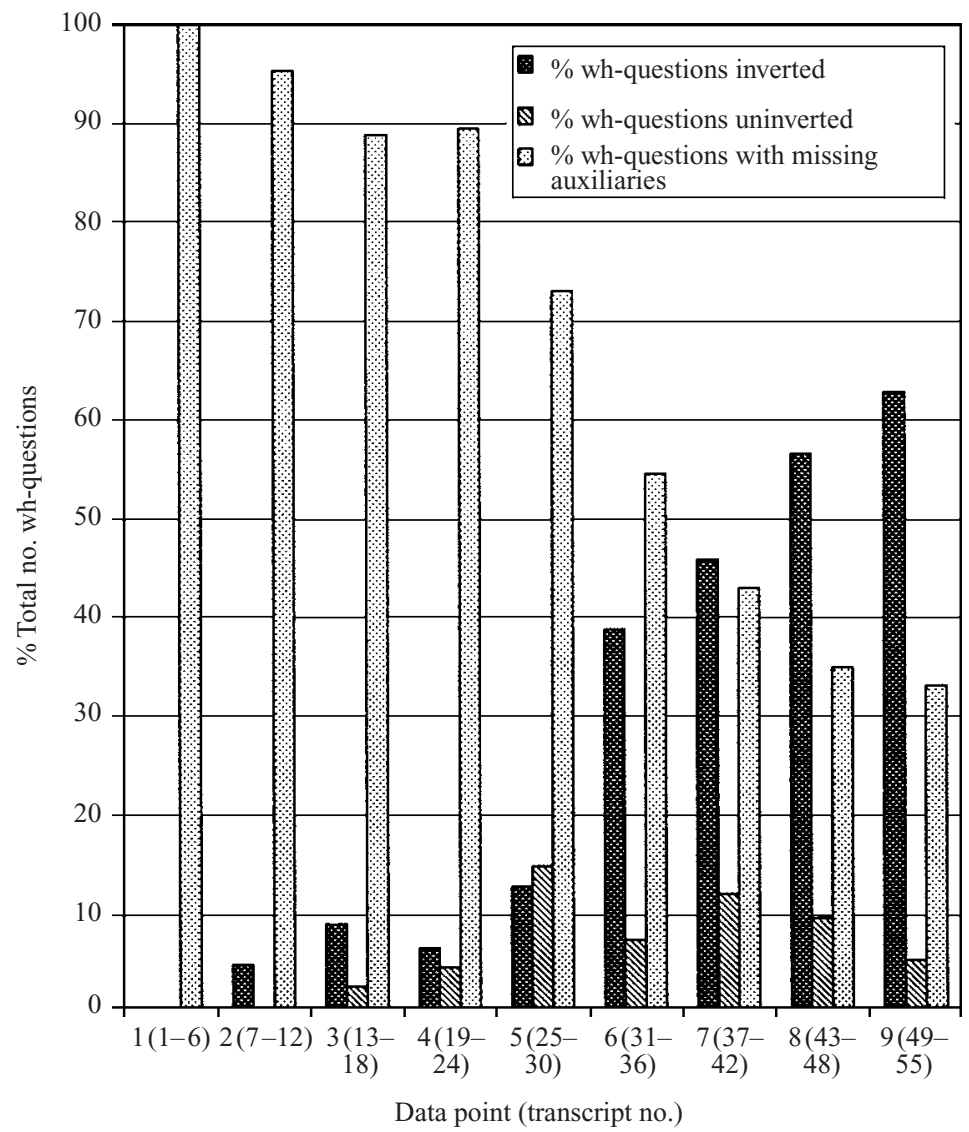

Fig. I. Percentage of wh-questions with inverted, uninverted and missing auxiliaries as a proportion of total number of wh-questions produced in the child's data. Data from Rowland $\&$ Pine (2000).

and finally, quite suddenly, starts to include inversion more often (datapoints $6+)$. Van Valin argues that at about datapoint 6 'something major has happened in his (Adam's) grammar concerning wh-questions' (Van Valin, 2002, p. I63); a dramatic shift in performance that R\&P cannot account for.

Third, Van Valin asserts that our explanation cannot account for the acquisition sequence of yes-no questions as it is concerned wholly with the acquisition of wh + aux combinations.

\section{Van Valin's alternative: Role and Reference Grammar (RRG)}

As an alternative to our explanation, Van Valin provides an account of the data couched in terms of RRG (e.g. Van Valin \& La Polla, I997). He argues that 



Who has presented an award to Pat?

(c)
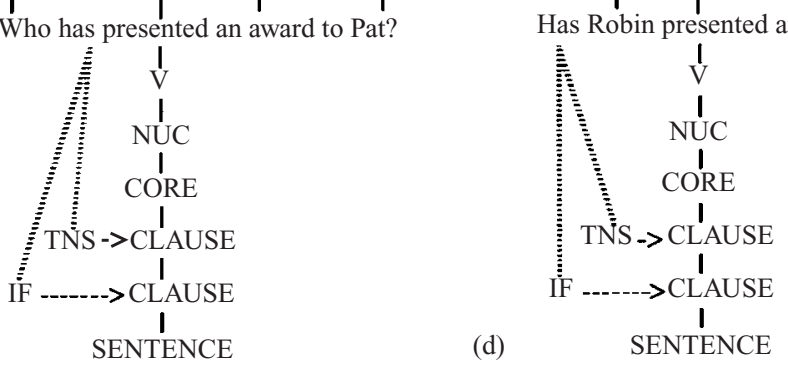

Fig. 2. RRG syntactic representations (simplified). Data from Van Valin (2002).

the key to the explanation is the analysis of illocutionary force (IF) marking in English. In English, IF is signalled by the position of the tense-bearing morpheme. Tense appears core-internally in declaratives but core-initially in interrogatives (i.e. before the subject) (see Figure 2 for simplified RRG representations, reproduced from Van Valin, 2002). Auxiliaries, since they 
carry tense, must occur in the pre-subject position in object and adjunct whquestions. However, in order for the child to realize that the auxiliary must be inverted $\mathrm{s} /$ he has to learn that the auxiliary carries tense. This is a harder task for modals (which are not clearly tensed) and negatives (which end in $n$ ' $t$ which does not signal tense) than for overtly tensed auxiliaries. According to this account then, the first auxiliaries to occur inverted will be overtly tensed auxiliaries (e.g. did, is), followed by negatives (e.g. didn't, couldn't) and modals (e.g. can, could). As Van Valin observes, most of Adam's inverted wh + aux combinations occur with tensed auxiliaries and most of his uninverted wh+ aux combinations occur with modals and negatives. There are a few exceptions in the data but most of these can be explained in terms of Adam just starting to learn to invert with modals or as a result of the peculiar properties of why which mean that it 'resist(s) inversion' (Van Valin, 2002, p. I69). In this way, the RRG account explains much of the data presented in the original Table 5 (see Table I above).

In order to explain the data presented in Figure I, Van Valin suggests three possible routes of interrogative acquisition, argues that examples of all three children can be found in the literature and states that the data from Adam accords with route 2 . A child following route 2 will treat the RRG statement 'tense appears core initially in interrogatives' as applying to yes-no questions only. In wh-questions, the child will treat the wh-word, not inversion, as the indicator of interrogative IF, which means that there will be a period of little inversion until $\mathrm{s} / \mathrm{he}$ realises that the initial wh-word does not signal IF and hence switches to inversion as the signal. This realization engenders a period of increasing inversion; with overtly tensed auxiliaries appearing with inversion before modals and negatives. Adam's data is explained in these terms. At datapoint 6, Adam is said to realize that inversion signals IF, which explains why there is a sudden and dramatic increase in the proportion of wh-questions that appear with inversion at this point.

Finally, Van Valin claims that this hypothesis, unlike that of R\&P can explain both wh- and yes-no question acquisition.

\section{Re-evaluating the two accounts}

To an extent, we agree with some of Van Valin's criticisms. In particular, Van Valin is correct in pointing out that R\&P's explanation as it stands does not incorporate an explanation of yes-no question acquisition. He is also right in his claim that the pattern of inversion/non-inversion in Adam's data cannot wholly be explained in terms of the lexical frequency statistics of the input. In fact, we acknowledge that implicit in $\mathrm{R} \& \mathrm{P}$ is an overestimation of the importance of the gross lexical frequency statistics of the input in acquisition.

However, we would argue that neither of these criticisms invalidates the approach we are taking in principle. For example, while the R\&P study does 
not include an explanation of yes-no questions, this is not the same as stating that yes-no question acquisition cannot be explained in similar terms. Based on the approach taken in $\mathrm{R} \& \mathrm{P}$ we could predict that there would be an association between the acquisition of particular auxiliary + subject combinations and the frequency with which these combinations occur in the child's input. Although this prediction has not yet been tested it does demonstrate that the approach taken in $\mathrm{R} \& \mathrm{P}$ could be extended in a principled way to account for yes-no question acquisition.

Second, while we agree that the input-driven approach cannot explain all the wh-question acquisition data, it does provide an account of a real effect the association between inversion/non-inversion in Adam's speech and the frequency with which wh + aux combinations occur in the mother. In fact, the size of the effect gets larger, not smaller, when we expand the input sample. We have repeated the original analysis but included in the input sample all the mother wh-questions that are present in the Adam corpus (tapes $\mathrm{I}-55$; Table 2). ${ }^{1}$ As predicted by R\&P, Adam's inverted wh + aux combinations were significantly more frequent inverted in the input than his uninverted wh + aux combinations $\left(\right.$ Median $=9 \cdot 5$ vs. Median $=0.5$, Mann-Whitney $U=\mathrm{I}_{5} \mathrm{I}, z=$ $-2 \cdot 45, n_{\mathrm{I}}=26, n_{2}=20, p<0 \cdot 02,2$-tailed). Thus, although there remains much to be explained, it is still a fact that there is a strong association between the input frequency of particular wh + aux combinations and the acquisition of correctly inverted wh-questions in Adam's speech. This association remains to be explained by any other account, including that of Van Valin.

These points aside, Van Valin's theory does seem to fit the summary data presented in $\mathrm{R} \& \mathrm{P}$ better than the input account. In particular, it seems to us that the strongest feature of the RRG model is its ability to explain the sudden rise in inversion and corresponding fall in errors in Adam's speech during datapoints 6 and 7. The presence of this pattern of data is also the most damaging part of Van Valin's critique of R\&P. ${ }^{2}$ However, the success of the RRG theory at explaining this pattern of data is partly due to a number of

[I] The expanded sample was not used in the original study in order to control for the effects of the child on the mother. In the present analysis, because mother and child data from the same tapes are used, this is a possible confounding variable. However, the correlation between the frequency of wh + aux combinations in the input during the first and last $\mathrm{r} O$ tapes is highly significant $(r=0.7 \mathrm{I} 7, n=48, p<0.0 \mathrm{I})$; suggesting that the child's level of development is not having a major effect on the relative frequency with which Adam's mother is producing wh + aux combinations.

[2] Note, however, that the rise in inversion should be considered in the light of the fact that we have only a sample of Adam's data, collected over an extensive period of acquisition. Thus, although there is a real phenomenon to be accounted for, if the sample of data is at all representative of Adam's speech as a whole, we should be aware that in this context 'sudden' is a relative term. If it were possible to conduct the same analysis on a week-by-week or even a day-by-day basis, we would presumably see a much gentler rise in the acquisition of inversion. Our thanks are due to an anonymous reviewer for signalling the importance of this point. 
TABLE 2. Total number of wh + aux combinations that occur inverted and/or uninverted during the non-inversion period and their frequency in the expanded input sample

\begin{tabular}{|c|c|c|c|c|c|}
\hline $\begin{array}{l}\text { Inverted } \\
\text { wh + aux }\end{array}$ & $\begin{array}{l}\text { No. in input } \\
\text { sample }\end{array}$ & $\begin{array}{l}\text { Uninverted } \\
\text { wh }+ \text { aux }\end{array}$ & $\begin{array}{l}\text { No. in input } \\
\text { sample }\end{array}$ & $\begin{array}{c}\text { Inverted \& } \\
\text { uninverted } \\
\text { wh }+ \text { aux }\end{array}$ & $\begin{array}{l}\text { No. in input } \\
\text { sample }\end{array}$ \\
\hline where had & $\mathbf{o}$ & how can't & $\mathbf{o}$ & why is & 6 \\
\hline which does & o & what may & $\mathbf{o}$ & how can & 43 \\
\hline who are & $\mathbf{o}$ & where should & $\mathbf{o}$ & what' is & I 8 \\
\hline who're & o & which should & o & & \\
\hline what'has & o & why'is & o & & \\
\hline what am & I & why can & o & & \\
\hline what have & $\mathbf{I}$ & why couldn't & $\mathbf{o}$ & & \\
\hline where shall & $\mathbf{I}$ & why'has & o & & \\
\hline where'is & 2 & why might & $\mathbf{o}$ & & \\
\hline who do & 2 & why won't & $\mathbf{o}$ & & \\
\hline where could & 2 & what should & $\mathbf{I}$ & & \\
\hline what was & 3 & why doesn't & $\mathbf{I}$ & & \\
\hline how could & 5 & why can't & $\mathbf{I}$ & & \\
\hline where do & I4 & why didn't & 2 & & \\
\hline how does & I4 & where will & 5 & & \\
\hline where does & I9 & what can & 6 & & \\
\hline what is & 23 & what shall & 9 & & \\
\hline how did & 32 & what will & 26 & & \\
\hline what're & 43 & why did & 29 & & \\
\hline where did & 50 & why don't & I 67 & & \\
\hline why do & 58 & & & & \\
\hline how do & 62 & & & & \\
\hline what are & 71 & & & & \\
\hline what does & 78 & & & & \\
\hline what did & II 7 & & & & \\
\hline what do & I69 & & & & \\
\hline
\end{tabular}

The combinations that did not occur in the original input sample are marked in bold.

parameters that are added to the basic premise of the theory. This basic premise states that at some point in development (datapoint 6 in Adam's data) children following route 2 realize that inversion is the primary morphosyntactic signal of interrogative IF. Before this, they analyse the wh-word as the interrogative IF indicator. Thus, in its purest form, the RRG theory would predict a strong stage-like shift in the acquisition data, from little or no inversion before the reanalysis to predominantly correct inversion after it.

However, this is not the case in Adam's data - a significant minority of inverted questions occur before datapoint 6 and there are a significant number of errors present after this point. In fact, the percentage of inverted questions rises by only $26 \%$ from $12 \cdot 6$ to $38 \cdot 6 \%$ of the total number of questions produced between datapoints 5 and 6 . The proportion of noninversion errors goes down by only $7 \cdot 5 \%$ between datapoints 5 and 6 and is actually higher at datapoint 7 ( I I $7 \%$ ) than at any previous datapoint except 
datapoint 5. In addition, although it is true to say that the percentage of inverted questions as a proportion of questions WITH auxiliaries rises suddenly (from $46 \cdot 3$ to $84 \cdot 5 \%$ ), the most frequent wh-questions at datapoint 6 are still auxiliary omission errors and there are significant amounts of omission even after datapoint 7 .

In order to explain why the rise in inversion is not more dramatic, the RRG theory needs three additional parameters. First, it has to assume that at datapoints $2-5$, Adam is capable of analysing inversion as a cue to IF but treats it as a redundant, unnecessary cue. This explains why he occasionally produces correctly inverted questions (albeit in small amounts) before datapoint 6 . Second, the RRG account has to posit that inversion will come in only gradually, starting with auxiliaries that can be easily identifiable as tensed, followed by modals and negatives that may be analysed as untensed for a period of time. Third, the account assumes that why resists inversion. ${ }^{3}$

None of these additional parameters is implausible in itself. Moreover, given that language acquisition is a complex process influenced by a variety of factors, the fact that the account has a number of parameters does not make it wrong. However, it is important to note that these parameters are motivated, in the main, by the data, not by the demands of the theory. Thus, although Van Valin's is a credible explanation of Adam's questions, this is at least in part because the theory is designed around the data. In order to ascertain its predictive validity, we need to test it further.

Since Adam has to learn that modals and negatives are tensed and that questions with why resist inversion, it seems to us that we should exclude these questions from tests of the prediction about the shift in grammatical knowledge said to occur at datapoint 6 . In fact, according to RRG, it should be these questions that are smoothing out the curve in Figure I and concealing a more dramatic shift from errors to correct inversion. The real prediction of Van Valin's theory as we see it is that there should be a shift from non-inversion to inversion for non-why questions that occur with tensed, non-negated auxiliaries. Unfortunately, when we investigate Adam's data we find that this is not the case (see Table 3$){ }^{4}$

[3] These last two parameters are included in Van Valin's account in order to explain the pattern of inversion and non-inversion presented in Table 5 of R\&P. As such, it could be argued that they only apply when Adam is in the non-inversion stage, and cannot be incorporated into an explanation of why Adam produces errors after datapoint 6 . However, if this was the case, Van Valin's theory would not present an explanation of why errors occur at all after datapoint 6 . Thus, we have made the assumption that these parameters still apply even after the hypothesized shift in Adam's grammatical knowledge.

[4] It would be more consistent with $\mathrm{R} \& \mathrm{P}$ to include wh-questions with omitted auxiliaries in this analysis and to present inversion as a proportion of the total number of wh-questions produced with tensed auxiliaries. However, since it is not possible to distinguish omitted modals and negatives from omitted forms of $d o$, we cannot present the results in this way. 
TABLE 3. Number of wh-questions with tensed, non-negated auxiliaries and whwords other than W HY that occur with inverted and uninverted auxiliaries at each datapoint

\begin{tabular}{lcc}
\hline Datapoint & No. inverted & No. uninverted \\
\hline I & $\circ$ & $\circ$ \\
2 & 3 & $\circ$ \\
3 & 7 & $\circ$ \\
4 & $\mathrm{I} 3$ & $\mathrm{I}$ \\
5 & 30 & $\circ$ \\
6 & 70 & $\circ$ \\
7 & 62 & 3 \\
8 & 38 & 5 \\
\hline
\end{tabular}

Although there is a large increase in the number of inverted wh-questions produced at datapoint 5 and another at datapoint 6 , there is, importantly, no shift from non-inversion to inversion for this subset of wh-questions. In fact, for these questions, there is very little evidence for non-inversion at all - they tend to occur inverted all the way through the developmental period under study. What this means is that nearly all non-inversion is explained by the additional parameters. The implication is that, contrary to Van Valin's predictions, a shift in Adam's knowledge about the correct morphosyntactic marker of IF seems not to be the causal factor in the rise in inversion provision at datapoint 6 .

In fact, the rise in correct production at datapoint 6 is mainly attributable to two other factors, neither of which indicates a significant change in the nature of Adam's grammatical knowledge about wh-question construction. First, Adam starts to use a wider range of wh-words with the auxiliaries that he has used inverted at previous datapoints. Questions with auxiliaries that have occurred inverted at previous datapoints but that are used for the first time with a particular wh-word at datapoint 6 account for 27 of the 76 different whquestions produced at datapoint $6(35 \cdot 53 \%$; see Table 4$)$. The most significant of these wh+aux patterns is how does which is used for the first time at datapoint 6 and which occurs 14 times (constituting $18 \cdot 42 \%$ of the questions produced); previously, does had only occurred with what. Second, Adam starts to use the wh + aux patterns he has already used inverted at previous datapoints in a wider range of wh-question types. ${ }^{5}$ These wh + aux patterns account for the majority of the wh-questions produced at datapoint 6 (45 questions; $59 \cdot 2$ I \% of the total; see Table 4$)$. In fact, $37(48 \cdot 68 \%)$ of the whquestions produced at datapoint 6 are attributable to only three wh + aux patterns (how do, what are, what do), all of which have been used at earlier datapoints.

[5] It should be noted that all analyses here and in $\mathrm{R} \& \mathrm{P}$ are conducted on wh-question types not tokens. 
TAB LE 4. Auxiliaries and wh+aux patterns produced at datapoint 6 and the number of times they occur in different wh-questions

\begin{tabular}{|c|c|c|c|}
\hline Auxiliary & $\begin{array}{l}\text { No. of } \\
\text { occurrences } \\
\text { (\% of total) }\end{array}$ & Wh + aux pattern & $\begin{array}{l}\text { No. of } \\
\text { occurrences } \\
\text { (\% of total) }\end{array}$ \\
\hline Are & $10(13 \cdot 16)$ & $\begin{array}{l}\text { what are } \\
\text { who are }\end{array}$ & $\begin{array}{l}9(\mathrm{Ir} \cdot 84) \\
\mathrm{I}(\mathrm{I} \cdot 32)\end{array}$ \\
\hline Can & $I(1 \cdot 32)$ & how can & $I(1 \cdot 32)$ \\
\hline Could & $2(2 \cdot 63)$ & $\begin{array}{l}\text { how could } \\
\text { where could }\end{array}$ & $\begin{array}{l}I(I \cdot 32) \\
I(I \cdot 32)\end{array}$ \\
\hline Did & $6(7 \cdot 89)$ & $\begin{array}{l}\text { how did } \\
\text { what did }\end{array}$ & $\begin{array}{l}5(6 \cdot 58) \\
\mathbf{I}(\mathbf{I} \cdot 32)\end{array}$ \\
\hline Do & $33(43 \cdot 42)$ & $\begin{array}{l}\text { how do } \\
\text { what do } \\
\text { where do } \\
\text { who do } \\
\text { why do }\end{array}$ & $\begin{array}{l}\text { I2 (15.79) } \\
\text { I6 (2I.05) } \\
3(3.95) \\
\text { I ( }(1 \cdot 32) \\
\text { I (I.32) }\end{array}$ \\
\hline Does & $20(26 \cdot 32)$ & $\begin{array}{l}\text { how does } \\
\text { what does } \\
\text { where does } \\
\text { which does }\end{array}$ & $\begin{array}{c}\text { I } 4(\mathbf{1} 8 \cdot 42) \\
\mathbf{I}(\mathbf{I} \cdot \mathbf{3 2}) \\
3(3 \cdot 95) \\
2(2 \cdot 63)\end{array}$ \\
\hline $\begin{array}{l}\text { Had } \\
\text { Is }\end{array}$ & $\begin{array}{l}I(I \cdot 32) \\
2(2 \cdot 63)\end{array}$ & $\begin{array}{l}\text { where had } \\
\text { what is } \\
\text { why is }\end{array}$ & $\begin{array}{l}\text { I }(\mathrm{I} \cdot 32) \\
\text { I }(\mathrm{I} \cdot 32) \\
\text { I }(\mathrm{I} \cdot 32)\end{array}$ \\
\hline shall & I $(I \cdot 32)$ & where shall & $\mathrm{I}(\mathrm{I} \cdot 32)$ \\
\hline
\end{tabular}

Auxiliaries and wh + aux patterns that have occurred at previous datapoints are presented in bold.

We would argue that these results suggest not that Adam has qualitatively different grammatical knowledge about inversion at datapoint 6 as Van Valin predicts, but that he is consolidating and expanding upon his knowledge of how particular auxiliaries behave. In particular, Adam seems to be learning how the wh + aux patterns what are, how do, what do and how does behavethese four wh + aux patterns account for 5 I $(67 \cdot$ I I \% ) of all his inverted whquestions at datatpoint 6 . It is worth noting that this pattern of results is compatible with the explanation proposed by Rowland \& Pine (2000), which states that as well as learning new combinations, children are generalizing across wh-words and auxiliaries that share distributional characteristics and are building up knowledge of how to use already acquired wh + aux combinations in a greater variety of wh-structures.

Finally, although it may be the case that inversion tends to occur first with tensed auxiliaries as Van Valin would predict, we need to investigate whether the incidence of NON-INVERSION follows the corresponding pattern. Since tensed auxiliaries should be the first to occur with inversion, we would expect to see a decrease in the incidence of non-inversion errors with tensed auxiliaries after datapoint 6 . However, this prediction is not upheld (see Table 5). Tensed auxiliaries account for a greater proportion of Adam's uninverted 
TABLE 5. Number of uninverted wh-question types that occur with tensed auxiliaries, modals and negatives at datapoints 3-8

\begin{tabular}{lccc}
\hline Datapoint & $\begin{array}{c}\text { Tense }(\% \text { of } \\
\text { uninverted qs) }\end{array}$ & $\begin{array}{c}\text { Modal (excluding } \\
\text { negated modals) } \\
(\%)\end{array}$ & $\begin{array}{c}\text { Negative (including } \\
\text { negated modals) } \\
(\%)\end{array}$ \\
\hline 3 & I (50) & 0 & I $(50)$ \\
4 & $2(22 \cdot 22)$ & $2(22 \cdot 22)$ & $5(55 \cdot 56)$ \\
5 & $3(8 \cdot \mathrm{I})$ & $22(59 \cdot 46)$ & $9(64 \cdot 29)$ \\
6 & $2(\mathrm{I} 4 \cdot 29)$ & $3(2 \mathrm{I} \cdot 42)$ & $8(33 \cdot 33)$ \\
7 & $\mathrm{I} 3(54 \cdot \mathrm{I} 7)$ & $3(\mathrm{I} 2 \cdot 50)$ & $2(\mathrm{I} 5 \cdot 38)$ \\
\hline
\end{tabular}

No uninverted questions occurred at datapoints I and 2.

wh-questions at the later datapoints 7 and 8 than at the earlier ones $(4,5$ and 6$)$. In other words, Adam is actually producing MORE non-inversion errors with tensed auxiliaries at precisely the point at which he is predicted to be producing fewer of these errors.

In fact, it could be argued that the data is more consistent with the input explanation. The order of acquisition of inversion for these uninverted wh + aux combinations (i.e. the order in which the uninverted wh + aux combinations start to occur inverted in Adam's speech after the end of the noninversion period) is highly correlated with the frequency of these combinations in the input (Spearman's rho $=0.66, N=20, p<0.002$, see Table 6). In other words, the frequency with which the uninverted wh + aux combinations occur inverted in the input is correlated with the order with which Adam starts to use these combinations with inversion.

To summarize, although the RRG account successfully explains the summary data presented in $\mathrm{R} \& \mathrm{P}$, a closer examination of the fine detail of Adam's data reveals some inconsistencies. Despite the fact that, as Van Valin has identified, Adam produces more inverted wh-questions at datapoint 6 than at previous datapoints, there is little evidence that this rise is caused by a dramatic shift in the nature of Adam's grammatical knowledge. In fact, we would argue, the data is more consistent with our lexical approach. This approach predicts that Adam will be learning how auxiliaries and wh-words behave in wh-questions piecemeal, building up knowledge of how to use particular wh+aux combinations and expanding and consolidating this knowledge gradually as his experience of question construction grows, mediated in part by the frequency with which he hears particular wh + aux patterns.

CONCLUSION

In a sense, Van Valin's account is similar to the formalist theories of de Villiers (I99I) and Valian et al. (I992) that were considered in R\&P. Although the 
TA B LE 6. Order of acquisition of inversion for originally uninverted wh + aux combinations and frequency of these combinations in the input

\begin{tabular}{lll}
\hline $\begin{array}{c}\text { Wh +aux } \\
\text { combination }\end{array}$ & Tape number & $\begin{array}{c}\text { Input } \\
\text { frequency }\end{array}$ \\
\hline $\begin{array}{ll}\text { how can't } \\
\text { what may }\end{array}$ & Never inverted & $\circ$ \\
where should & 38 & $\circ$ \\
why'is should & 53 & $\circ$ \\
why can & Never inverted & $\circ$ \\
why couldn't & Never inverted & $\circ$ \\
why'has & Never inverted & $\circ$ \\
why might & Never inverted & $\circ$ \\
why won't & Never inverted & $\circ$ \\
what should & Never inverted & $\circ$ \\
why doesn't & Never inverted & $\circ$ \\
why can't & 52 & I \\
why didn't & 40 & I \\
where will & 43 & I \\
what can & 44 & 2 \\
what shall & Never inverted & 5 \\
what will & 38 & 6 \\
why did & 45 & 9 \\
why don't & 4 I & 26 \\
\hline & 38 & 67 \\
\hline
\end{tabular}

RRG account is not a formalist theory, it shares with them the idea of explaining acquisition by working backward from the linguistic theory that characterises the endpoint of acquisition (the adult grammar). According to Van Valin, this approach is superior to that taken in R\&P because 'the study of complex phenomena like the acquisition of syntax requires a well-defined linguistic theory to characterize the form and content of the linguistic knowledge to be acquired' (Van Valin, 2002, p. I74).

However, we would dispute that linguistic theory is 'an essential prerequisite for the explanatory study of the acquisition of grammar' (Van Valin, I 99 I, p. I 2). In our view, defining the endpoint of acquisition is important but it is not necessary to define it in terms of linguistic theory. Linguistic theories are descriptions of the adult phenomenon (the adult language) and as such, they may be useful descriptive tools, but they are not synonymous with the phenomenon itself. Acquisition theories are required to account for the emergence of the phenomenon, not for the emergence of the linguistic description.

In addition, it may at times be a disadvantage to view acquisition in terms of linguistic theorizing about the adult state. Defining the endpoint in these terms means that development is seen in terms of acquiring the linguistic rules that are used by the theory to describe the adult state. In other words, most linguistic theories, by their very nature, view acquisition in terms of 'big' rules 
(such as the inversion rule) that must apply to a grammatical category or a linguistically definable subset of a category such as overtly tensed auxiliary. Within these terms there are only two possible scenarios: the presence of a rule or its absence. The potential consequence of such an approach is that the theory may overlook the fact that the child's knowledge may be of a much more restricted nature (see e.g. Braine, I 976; Kuczaj \& Brannick, I 979; Kuczaj \& Maratsos, I983; Ninio, I988; Tomasello, ı992; Lieven, Pine \& Baldwin, I 997; Pine, Lieven \& Rowland, I998; Theakston, Lieven, Pine \& Rowland, 200I).

In the case of Adam's wh-question acquisition, the data do not show the type of all or nothing approach such 'big rules' predict. This means that additional parameters have to be added to explain the data because the constraints of linguistic theorizing do not admit the possibility that such big rules are not being acquired. These parameters explain why a child who must have a rule (because s/he occasionally inverts) does not always do so. De Villiers (I99i) assumes adjunct wh-questions are misanalysed, Valian et al. (I992) assume that children have to learn how to apply inversion wh-word by wh-word and Van Valin (2002) assumes that children learn to apply inversion to tensed auxiliaries before modals and negatives. However, even with these provisos, the theories cannot fully explain the restricted nature of Adam's data, nor can they explain why there is little evidence in the data for a qualitative shift in grammatical knowledge at a defined point in development.

The advantage of 'input-driven' or as we would prefer, 'data-driven' approaches is that they can admit the possibility that acquisition is not a case of acquiring 'big rules', and they can do this precisely because they are not constrained by current characterizations of the adult grammar. In fact, because these theories take what is observable in the data as their starting point, they are less likely to overestimate both the data and the extent of the child's knowledge that is evident in it. Of course, they may underestimate the child's knowledge but they do this because of the limitations of the data itself; a problem that can be minimized by more sophisticated methodological techniques.

Data-driven approaches are at least a viable alternative to theory-driven acquisition theories. In addition, we would argue that our data-driven account provides a relatively successful explanation of Adam's wh-question data. In particular, the data seem most consistent with an account that sees acquisition in terms of the gradual learning of, and generalization from, particular lexically specific wh + aux combinations rather than in terms of the acquisition of a category-general rule. More importantly, the fact remains that there is an association between the frequency with which wh + aux combinations occur in the mother and the pattern of inversion/non-inversion in Adam's speech, which, so far, is explicable only in terms of the input frequencies account advocated in R\&P. 
We do not wish to state that ALL children's acquisition data can be explained in terms of input frequencies (in fact, this claim would not be upheld by the data). As Slobin ( I 997) has suggested, a theory of language acquisition will have to incorporate the impact of a variety of interacting psycholinguistic and non-linguistic factors. However, given that the speech that a child hears is perhaps the most direct, easily observable influence on language acquisition, we would argue that this is a good starting point for an explanation. In the R\&P paper we have, we believe, presented the beginnings of explanation of how children may start to learn wh-question formation; not by the application of 'big rules', whether transformational or based on RRG, but by the simple expedient of picking up particular wh-word + auxiliary patterns from the input. What children do with these formulae later, how these formulae translate through development to adult knowledge and what type of knowledge underlies this development was not the focus of the R\&P paper. All we claim is that it is unnecessary to devise complex linguistic accounts of phenomena that may be explained more simply in terms of input frequencies or the distributional statistics of English.

\section{REFERENCES}

Braine, M. D. S. (1976). Children's first word combinations. Monographs of the Society for Research in Child Development 4I (I, Serial No. I64).

Brown, R. (1973). A first language: the early stages. Cambridge, MA: Harvard University Press. De Villiers, J. (I99I). Why questions? In T. L. Maxfield \& B. Plunkett (eds), Papers in the acquisition of wh: proceedings of the Umass roundtable, May I990. Amherst, MA: University of Massachusetts Occasional Papers.

Kuczaj, S. A. \& Brannick, N. (I979). Children's use of the wh-questions modal auxiliary placement rule. Fournal of Experimental Child Psychology 28, 43-67.

Kuczaj, S. A. \& Maratsos, M. P. (1983). Initial verbs of yes-no questions: a different kind of general grammatical category. Developmental Psychology 19, 440-4.

MacWhinney, B. (2000). The CHILDES project: tools for analyzing talk. Mahwah, NJ: Erlbaum.

Ninio, A. ( 1988 ). On formal grammatical categories in early child language. In Y. Levy, I. M. Schlesinger \& M. D. S. Braine (eds), Categories and processes in language acquisition. Hillsdale, NJ: Erlbaum.

Lieven, E. V. M., Pine, J. M. \& Baldwin, G. (1997). Lexically-based learning and early grammatical development. Fournal of Child Language 24, i 87-2 I 9.

Pine, J. M., Lieven, E. V. M. \& Rowland, C. F. (1998). Comparing different models of the development of the English verb category. Linguistics 36, 807-30.

Rowland, C. F. \& Pine, J. M. (2000). Subject-auxiliary inversion errors and wh-question acquisition: What children do know? Fournal of Child Language 27, I 57-8 I.

Slobin, D. (1997). The universal, the typological and the particular in acquisition. In D. Slobin (ed.). The cross-linguistic study of language acquisition; volume 5, Expanding the contents. NJ : Erlbaum.

Tomasello, M. (1992). First verbs : a case study of early grammatical development. Cambridge: CUP.

Theakston, A. L., Lieven, E. V. M., Pine, J. M. \& Rowland, C. F. (200I). The role of performance limitations in the acquisition of verb-argument structure: an alternative account. Fournal of Child Language 28, 127-52. 
Valian, V., Lasser, I. \& Mandelbaum, D. (I 992). Children's early questions. Paper presented at the I7th annual Boston University conference on language development.

Van Valin, R. D. (I99I). Functionalist linguistic theory and language acquisition. First Language $\mathbf{I}, 7-40$.

Van Valin, R. D. (2002). The development of subject-auxiliary inversion in English wh-questions: an alternative analysis. Fournal of Child Language 29, I6 I-75.

Van Valin, R. D. \& La Polla, R. (1997). Syntax: structure, meaning and function. Cambridge: CUP. 